\title{
Instantaneous Current Prediction for Naval Operations
}

\author{
Peter C. Chu \\ Naval Ocean Analysis and Prediction Laboratory, Department of Oceanography \\ Naval Postgraduate School, Monterey, CA 93943 \\ Albert E. Armstrong \\ Naval Ocean Analysis and Prediction Laboratory, Department of Oceanography \\ Naval Postgraduate School, Monterey, CA 93943
}

\begin{abstract}
Naval operations depend highly upon environmental conditions that can either adversely affect successful completion or hinder the safety of personnel. Each warfare community has defined environmental thresholds and operating limits that restrict the execution of any intended maneuver. As the warfare environment continues to shift from the open ocean to the littoral, prediction of the shallow water environment is an urgent need in order to support these operations. The value-aided of using a hydrodynamic model (WQMAP) for the mission planning of the naval operations in San Diego Bay is demonstrated in this study. A new model verification procedure (i.e., compatibility verification) is proposed for the tidal dominated littoral basin prediction.
\end{abstract}

\section{INTRODUCTION}

Execution of any naval operation can be hindered by numerous marine environmental factors. Proper planning for these operations includes forecasting the environment of the area of operations. Each warfare area has defined environmental thresholds and operating limits that restrict the execution of any intended maneuver. Amphibious assault vehicles, mechanized landing craft, utility landing craft, AN/SLQ-48 mine neutralization vehicle aboard Avenger class mine countermeasures ships and Osprey class coastal mine hunter, and diver operations all have various ocean current thresholds. Littoral warfare oceanography is to study the measure of effectiveness of environmental information, to identify the environmental effects on littoral warfare (mine warfare, special warfare, homeland security, ...), to optimize war-fighting requirements using quantitative information of the environment, and to make an environmental planning aid for the war fighter (Armstrong, 2004).

Mine warfare (MIW) operations such as mine hunting and clearance are conducted with the condition that the instantaneous current speed is less than a threshold (c), $|\mathbf{V}| \leq c$. If the current speed is larger than $c$, the operation should be stopped. Since the tidal currents dominate the littoral zone, the National Oceanic and Atmospheric Administration (NOAA) tide table that provides maximum ebb and flood current speeds is used to schedule the operational period. For example, A MIW operation was conducted within San Diego Bay (Fig. 1) on 21 January 2004. The scenario is that just a day before a freighter exiting the bay was seen discharging several large objects in the vicinity of Station-4 (inside San Diego Bay) as it steams outbound for sea. A mine countermeasures ship should be dispatched to locate and identify the mine like objects utilizing its AN/SQQ-32 variable depth mine hunting sonar along with the AN/SLQ-48 mine neutralization vehicle. The current thresholds for these assets are operationally sensitive, so a fictitious and current limit of $1 \mathrm{~m} \mathrm{~s}^{-1}$ (i.e., 2 knots) will be used as an operational current threshold in this example. 


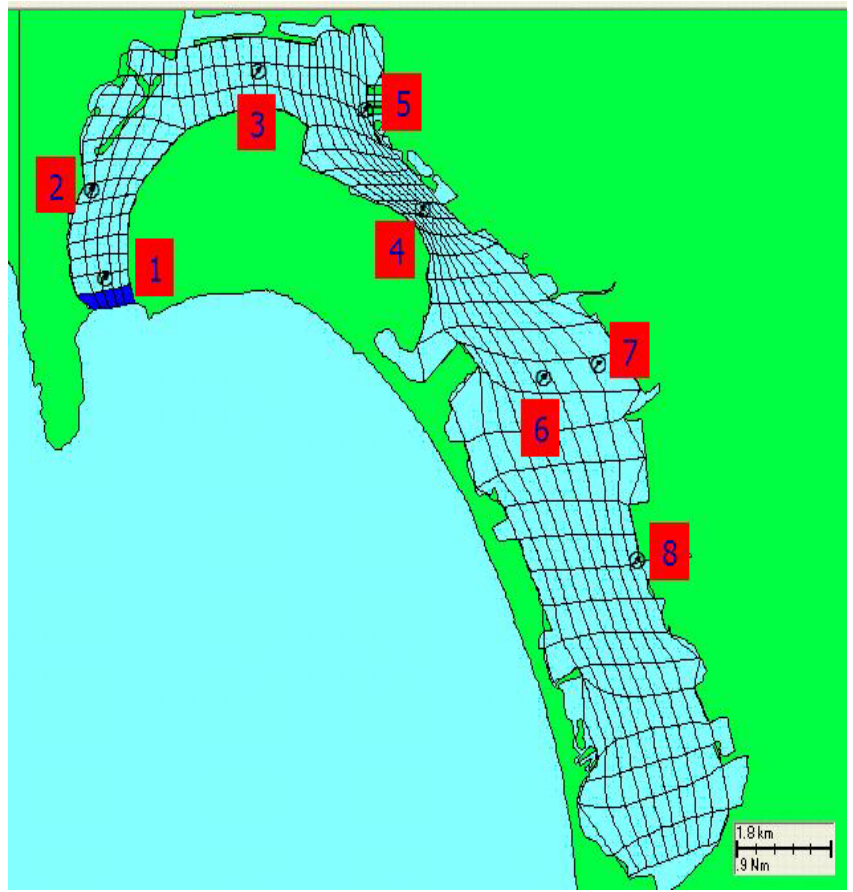

locations:

Fig. 1. San Diego Bay geography and several

Presently, the tidal current obtained from the NOAA tide table is the only source of environmental information for the Navy's MIW units to schedule the mine countermeasure operations. However, the NOAA tide table data are usually calculated at particular locations. For example, in San Diego Bay, the NOAA tidal current data are only available in the mouth of the Bay (i.e., Station-1) with four data points per day: two maximum ebb speeds and two maximum flood speeds. Usually, the dispatcher schedules the mine countermeasure ship operations at Station- 4 is on the base of the NOAA tide table data for Station-1 and the linear interpolation of four times daily data into high resolution time series. For the tidal current data shown in NOAA tidal table, the mine countermeasure can operate within the threshold $\left(1 \mathrm{~m} \mathrm{~s}^{-1}\right)$ all morning until 11:10. The mine hunting would be able to resume again around 13:45 with no other restrictions for the rest of the day (Fig. 2). Questions arise: Can the NOAA tidal current data for Station-1 be used for Station-4? Can the interpolation be used to get high temporal resolution data from the four times daily NOAA tidal current data? Assessment of existing technology is essential to answer these questions.

Recent advances in numerical modeling and computer hardware have made robust and efficient numerical models available. These models can provide sufficient spatial details to simulate tidal hydrodynamic processes in bays and estuaries. A $100-\mathrm{m}$ resolution (30,800 grid nodes), depth averaged, numerical hydrodynamic model was implemented for San Diego Bay to describe essential hydrodynamic processes in the bay. This two dimensional model was calibrated using the 1983 observed data and verified using
1992-1996 observed data [1]. Discrepancies between model prediction and field data in both model calibration and verification are on the order of the magnitude of uncertainties in the field data [2].

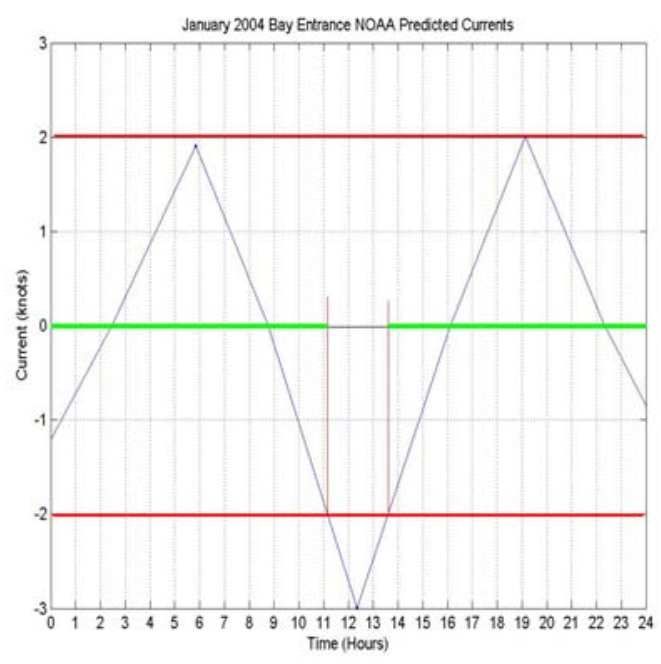

Fig. 2. Mission planning for mine countermeasure and mine hunting inside San Diego Bay using NOAA tide table maximum ebb and flood current velocities at Station-1.

In this study, a 2D hydrodynamic model similar to [2] with curve-linear coordinates and graphic use interface is used to predict instantaneous current velocity in San Diego Bay with high temporal and spatial resolutions using NOAA tide table data at Station-1. The model predicted current velocity at Station-4 (or other location inside San Diego Bay) can be used for scheduling the mine countermeasure ship or any other naval operations. The purpose of this study is to show the wide application of the littoral ocean models to the Navy operations.

The rest of this paper is outlined as follows. Section 2 describes general oceanographic conditions of San Diego Bay. Sections 3 presents a high-resolution hydrodynamic model (WQMAP) with boundary fitting curve-linear coordinates and graphic user interface. Sections 4-6 show the model implementation, tidal forcing, and compatibility verification. Sections 7-8 illustrate the application of the model prediction to the mission planning of the naval operations. Section 9 presents the conclusions.

\section{SAN DIEGO BAY}

San Diego Bay is located in southern California near the Mexican border and is the home port to a large fraction of the U. S. Navy's active fleet. The bay has been extensively engineered to accommodate shipping activities with a deep navigation channel in the northern part of the bay while the south part is very shallow. About $90 \%$ of all available marsh lands and $50 \%$ of all available inter-tidal lands have been reclaimed, and dredging activities within the 
bay have been equally extensive (Peeling, 1975). The San Diego River was diverted by the U. S. Army Corps of Engineers in 1875 and no longer empties into San Diego Bay.

San Diego Bay is a small crescent shape bay, 43 $\mathrm{km}^{2}$ in area at mean lower low water (MLLW), with an average depth of $6.5 \mathrm{~m}$ measured from the mean sea level. Maximum tidal range in the spring tides exceeds $2 \mathrm{~m}$, whereas the mean tidal range is about $0.85 \mathrm{~m}$. Tidal current speeds range between $0.3-0.5 \mathrm{~m} \mathrm{~s}^{-1}$ near the inlet and 0.1-0.2 $\mathrm{m} \mathrm{s}^{-1}$ in the southern region of the bay. Freshwater inflow to the bay is low and only occurs during infrequent winter storms. Westerly afternoon winds occur throughout the year and are about $5 \mathrm{~m} \mathrm{~s}^{-1}$; evening and early morning easterly winds occur primarily in winter and are less than $5 \mathrm{~m} \mathrm{~s}^{-1}$. Since freshwater flow in the bay is low as well as wind magnitude, currents are predominately produced by tides. Except during rare occasions, San Diego Bay can be treated as a vertically well-mixed estuary (Wang et al., 1998).

\section{HYDRODYNAMIC MODEL}

The numerical hydrodynamic model implemented for San Diego Bay is a depth-averaged, boundary fitted tidal and residual circulation model known as WQMAP ([4], [5]). The numerical techniques incorporated in the model are well documented, thus only a summary of the model characteristics is presented.

WQMAP is an integrated hydrodynamic and water quality modeling system designed for use within coastal and fresh water environments. This commercial off-the-shelf program was developed by Applied Science Associates, Inc. out of Narragansett, Rhode Island. WQMAP consists of three basic components: a boundary-fitted coordinate grid creation module, a three-dimensional hydrodynamics model, and a water quality or pollutant transport model. These models are executed on a boundary fitted grid system. They can also be operated on any orthogonal curvilinear grid or a rectangular grid, which are special cases of the boundary fitted grid. The model is configured to run in a vertically averaged (barotropic) mode or as a fully three-dimensional (baroclinic) mode. Several assumptions are made in the model formulation, including the hydrostatic (shallow water) approximation, the Boussinesq approximation, and incompressibility. In this study, the 2D version is used.

Most striking feature of WQMAP is its hybrid orthogonal curvilinear-terrain following coordinate system. Let $(\varphi, \lambda, z)$ be the latitude, longitude, and height, and $(\xi, \eta, \sigma)$ be a hybrid coordinate system with a generalized orthogonal curvilinear coordinate system $(\xi, \eta)$ in the horizontal and terrain-following $\sigma$-coordinate in the vertical. The metric coefficients connecting $(\phi, \lambda)$ to $(\xi, \eta)$ are defined by

$$
\begin{aligned}
& g_{11}=\left(\frac{\partial \lambda}{\partial \xi}\right)^{2} \cos ^{2} \phi+\left(\frac{\partial \varphi}{\partial \xi}\right)^{2}, \\
& g_{22}=\left(\frac{\partial \lambda}{\partial \eta}\right)^{2} \cos ^{2}+\left(\frac{\partial \varphi}{\partial \eta}\right)^{2} .
\end{aligned}
$$

The coefficient $\mathrm{g}_{11}$ is the metric tensor in $\xi$-direction and the coefficient $\mathrm{g}_{22}$ metric tensor in $\eta$-direction. These tensors permit the model to transform the user defined boundary fitted grid to a numerical grid employed for spatial discretization utilized in an Arakawa $C$ Grid.

Let $(\zeta, H)$ be the surface elevation and bathymetry. $D=H+\zeta$, is the total water depth. The $\sigma-$ and $\mathrm{z}-$ coordinates are connected by

$$
\sigma=\frac{z+H}{\zeta+H},
$$

which makes $\sigma=1$ for the ocean surface and $\sigma=0$ for the ocean bottom.

The 2D WQMAP represents a depth-averaged shallow-water system (similar to Wang et al., 1998). Let ( $U$, $V)$ be the vertically averaged velocity components in $(\xi, \eta)$ directions. The momentum equations for $(U, V)$ are given by

$$
\begin{aligned}
& \frac{\partial U D}{\partial t}+\frac{1}{\sqrt{g_{11} g_{22}}}\left[\frac{\partial\left(U^{2} D \sqrt{g_{22}}\right)}{\partial \xi}+\frac{\partial\left(U V D \sqrt{g_{11}}\right)}{\partial \eta}+U V D \frac{\partial\left(\sqrt{g_{11}}\right)}{\partial \eta}\right. \\
& \left.-V^{2} \frac{\partial\left(\sqrt{g_{22}}\right)}{\partial \xi}\right]-f D V=-\frac{g D}{R \sqrt{g_{11}}}\left[\frac{\partial \zeta}{\partial \xi}+\frac{D}{\rho_{0}} \int_{-1 \sigma}^{0} \int_{-1}^{0}\left(\frac{\partial \rho}{\partial \xi}-\frac{\sigma}{D} \frac{\partial D}{\partial \xi} \frac{\partial \rho}{\partial \sigma}\right) d \sigma\right] \\
& +\frac{1}{\rho_{0}}\left(\tau_{\xi}^{w}-\tau_{\xi}^{b}\right)+A_{h} D \nabla^{2} U,
\end{aligned}
$$

$$
\begin{aligned}
& \frac{\partial V D}{\partial t}+\frac{1}{\sqrt{g_{11} g_{22}}}\left[\frac{\partial\left(U V D \sqrt{g_{22}}\right)}{\partial \xi}+\frac{\partial\left(V^{2} D \sqrt{g_{11}}\right)}{\partial \eta}+U V D \frac{\partial\left(\sqrt{g_{22}}\right)}{\partial \xi}\right. \\
& \left.-U^{2} \frac{\partial\left(\sqrt{g_{11}}\right)}{\partial \eta}\right]+f D V=-\frac{g D}{R \sqrt{g_{22}}}\left[\frac{\partial \zeta}{\partial \eta}+\frac{D}{\rho_{0}} \int_{-1}^{0} \int_{-}^{0}\left(\frac{\partial \rho}{\partial \eta}-\frac{\sigma}{D} \frac{\partial D}{\partial \eta} \frac{\partial \rho}{\partial \sigma}\right) d \sigma\right] \\
& +\frac{1}{\rho_{0}}\left(\tau_{\eta}^{w}-\tau_{\eta}^{b}\right)+A_{h} D \nabla^{2} V .
\end{aligned}
$$

The continuity equation is represented by 
$R \sqrt{g_{11} g_{22}} \frac{\partial \zeta}{\partial t}+\frac{\partial\left(U D \sqrt{g_{22}}\right)}{\partial \xi}+\frac{\partial\left(V D \sqrt{g_{11}}\right)}{\partial \eta}=0$.

Here, $R$ is the earth radius; $\rho_{0}\left(=1025 \mathrm{~kg} \mathrm{~m}^{-3}\right)$ is the characteristic density for the seawater; $f$ is the Coriolis parameter; $g$ is the acceleration due to gravity; $A_{h}$ is the horizontal eddy viscosity; $\left(\tau_{\xi}^{w}, \tau_{\eta}^{w}\right)$ are the wind stress; and $\left(\tau_{\xi}^{b}, \tau_{\eta}^{b}\right)$ are the bottom stress. As with any depth-averaged model, it is implicitly assumed that velocity and density are nearly constant over the water column. However, horizontal density gradients are treated explicitly in the momentum equations. As we mentioned in Section 2 that the freshwater flow and surface winds in the bay are low. The currents in San Diego Bay are predominately produced by tides. Thus, the horizontal density gradient can be neglected in short-term prediction.

\section{MODEL IMPLEMENTAION}

WQMAP for San Diego Bay covers an area of 43 $\mathrm{km}^{2}$. Different from Wang et al. (1998), the model domain is only for the bay and the boundary fitting orthogonal curvelinear coordinates are used (Fig. 3). The computational mesh has $150 \times 150(22,500)$ grid nodes with an average horizontal resolution of $45 \mathrm{~m}$. Model bathymetry is determined from depth sounding data provided by NOAA and supplemented by data from published navigation charts. Recently Navy conducted bathymetry surveys show that the water depths in regions near the bay entrance are significantly deeper than the water depths shown on the NOAA navigation chart (Wang et al., 1998). The most up-to-date bathymetry data are used in the model (Fig. 4).

Water surface elevation and velocity are set to zero, and temperature and salinity are assigned as the characteristic values for San Diego Bay $\left(16^{\circ} \mathrm{C}, 34 \mathrm{ppt}\right)$ at all grid points. The model is allowed to "spin up" from quiescent initial condition for one day before any model results are used for analysis. A six-minute time step is chosen for time step. At this time step the CFL condition is satisfied. Besides, the model parameters are given as follows: the wind drag coefficient (0.0014), the bottom drag coefficient $(0.003)$, the vertical viscosity $\left(0.005 \mathrm{~m}^{2} \mathrm{~s}^{-1}\right)$, the vertical diffusivity $(0.001$ $\left.\mathrm{m}^{2} \mathrm{~s}^{-1}\right)$, and the horizontal diffusivity $\left(1.0 \mathrm{~m}^{2} \mathrm{~s}^{-1}\right)$.

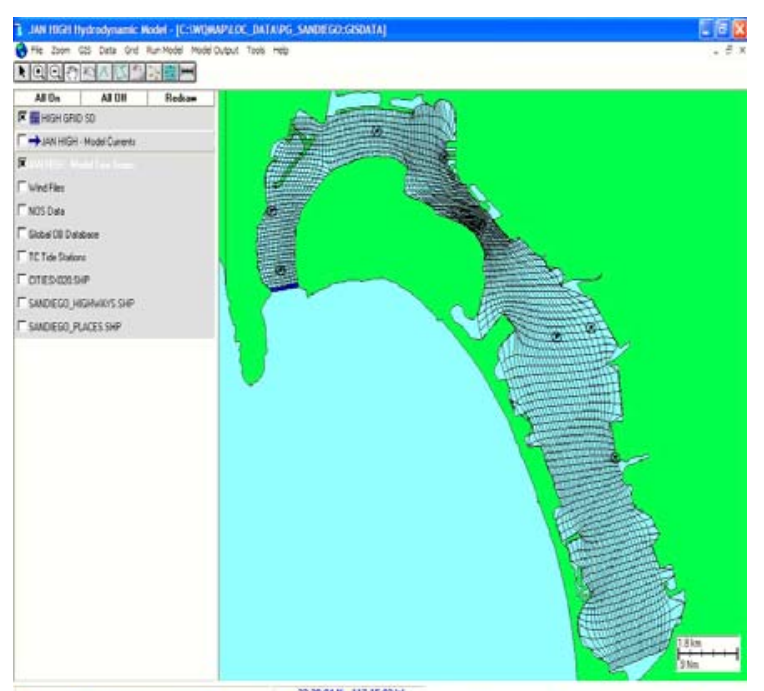

Fig. 3. Model grids.

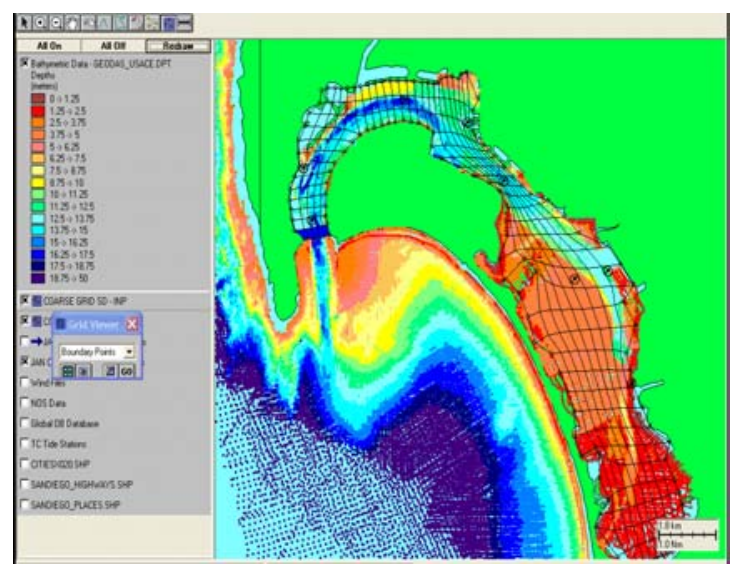

Fig. 4. San Diego Bay bathymetry.

\section{TIDAL FORCING}

Temporally varying sea surface elevation (or tidal harmonic constituents) along the open boundary (entrance of San Diego Bay) is taken as the model forcing function. Such data are available at the NOAA Center for Operational Oceanographic Products and Services website. The elevation data with six-minute interval are archived from time 0000 on 01 January 2004 to 2354 on 31 January 2004 for San Diego Bay entrance (Station Identification Number 9410170, i.e., Station-1 in Fig. 1). This data set consists of 7,440 lines of observed elevation data points and contains high-frequency non-tidal signals. The fast Fourier Transform is conducted on the data set, and the high frequency signals that was present within the data set from winds, fronts, etc were filtered out. The new smoothed elevation data are used as the tidal forcing function at the entrance of San Diego Bay. 


\section{COMPATIBILITY VERIFICATION}

Usually, the NOAA tidal table lists the surface elevation (6-min interval) and maximum ebb and flood current speeds (4 times daily). When the surface elevation data at the open boundary (i.e., Station-1 in Fig. 1) are used as the tidal forcing to drive the hydrodynamic model (i.e., WQMAP), temporally varying horizontal current velocity with horizontal resolution of around $45 \mathrm{~m}$ is generated for the whole San Diego Bay. Since the maximum ebb and flood current velocities at the open boundary (i.e., Station-1) from the NOAA tide table are not used to force the numerical model, it is important to check if the model generated current velocities near Station-1 consist with that in the NOAA tide table. This process is called the compatibility verification. If the model generated current velocities near the open boundary are different from that listed in the NOAA tide table, the model is dynamically incompatible at the open boundary. Otherwise, the model is dynamically compatible at the open boundary. Let $\left[v^{\text {WQMAP }}\left(t_{i}\right), v^{\text {NOAA }}\left(t_{i}\right)\right]$ be the model generated and the NOAA tide table listed ebb and flood current velocities. The mean relative error (MRE) between the two

$$
\text { MRE }=\frac{1}{M} \sum_{i} \frac{\left|v^{\text {WOMAP }}\left(t_{i}\right)-v^{\text {NOAA }}\left(t_{i}\right)\right|}{\left|v^{\text {NOAA }}\left(t_{i}\right)\right|},
$$

is used to identify the dynamical compatibility at the open boundary. Here, $M$ is the total number of data points. The less the MRE, the more dynamically compatible at the open boundary is. Usually, MRE $<10 \%$ can be used as the indication for the dynamical compatibility.

The NOAA tide table current velocity data used for the compatibility test (at Station-1) are in reference to a positive value for the flood direction of $355^{\circ}$ and a negative value for the ebb direction of $175^{\circ}$. The model-generated horizontal velocity in zonal and latitudinal components $(u$, $v ')$ should be transformed into $(u, v)$ in the ebb and flood directions for comparison with the NOAA tide table.

Fig. 5 shows the model generated (dashed curve) and the NOAA tide table listed (solid curve) ebb and flood currents at the open boundary (i.e., Station-1). The modeled velocity is highly in-phase with the NOAA tide table data. Modeled results are slightly over predicted in the flood currents and similarly under predicted in ebb currents. The initial large error in amplitude and phase is seen at the beginning of the model run and is primarily due to the ramp up time needed for the model to initialize. The model elevation forcing was already in place at the instant of the model run but initial current speed for the model initialization was zero meters per second. After a period of one day, the model nearly perfectly matches the phase and amplitude of the verification data. The MRE between the modeled currents and the NOAA tide table data set is $4.1 \%$, which shows the dynamical compatible at the open boundary.

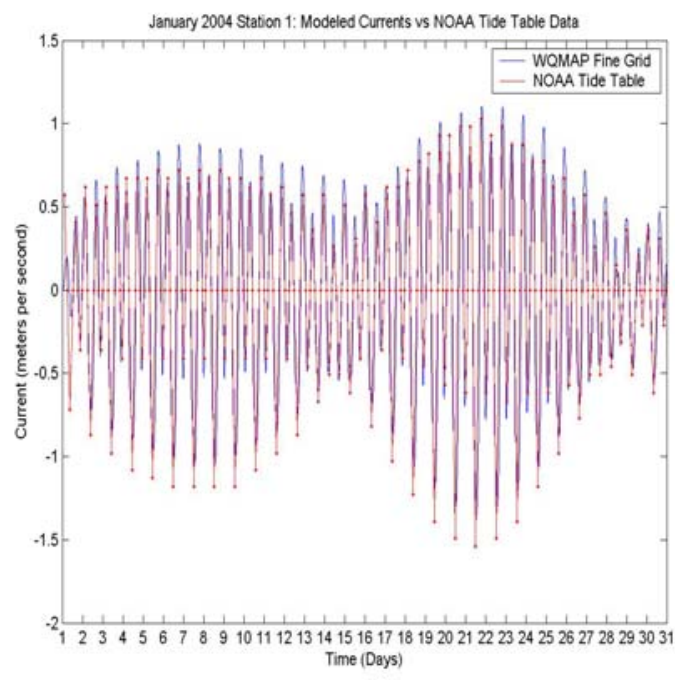

Fig. 5. Comparison between model generated and NOAA tide table listed maximum ebb and flood current velocities at Station-1 (compatibility verification).

Besides the compatibility test, the model generated current velocity inside the bay should be compared with the observational data such as the current meter data, acoustic Doppler current profile (ADCP) data, etc. ([6], [7]). Since the NOAA tide table is the easiest environmental source to obtain for most naval operations, and since the purpose of this study is to show the importance of the littoral zone modeling for Navy's operations, detailed verification is not described here.

\section{APPLICATION TO THE MIW EXERCISES}

Section 1 describes a simple mine warfare operation was conducted near Station-4 inside San Diego Bay on 21 January 2004. With the maximum ebb and flood current velocities at Station-1 (entrance of San Diego Bay) from the NOAA tide table, the mine countermeasure can operate within the threshold for current velocity $\left(1 \mathrm{~m} \mathrm{~s}^{-1}\right)$ all morning until 11:10. The mine hunting would be able to resume again around 13:45 with no other restrictions for the rest of the day (Fig. 2).

Fig. 6 shows the time series of the predicted ebb and flood current velocity at Station-4 on the same day (21 January 2004) using WQMAP with the tidal forcing at the open boundary (Station-1, from NOAA tide table). The model predicted current speed at Station-4 is much slower than the tidal current speed at Station-1 listed in NOAA tide table. Fig. 7 shows that the instantaneous speeds are all less than the threshold $\left(1 \mathrm{~m} \mathrm{~s}^{-1}\right)$. There is no need to interrupt mine countermeasure and mine hunting operations. Fig. 6. Comparison between model generated (at Station-4) and 
NOAA tide table listed (at Station-1) maximum ebb and flood current velocities.

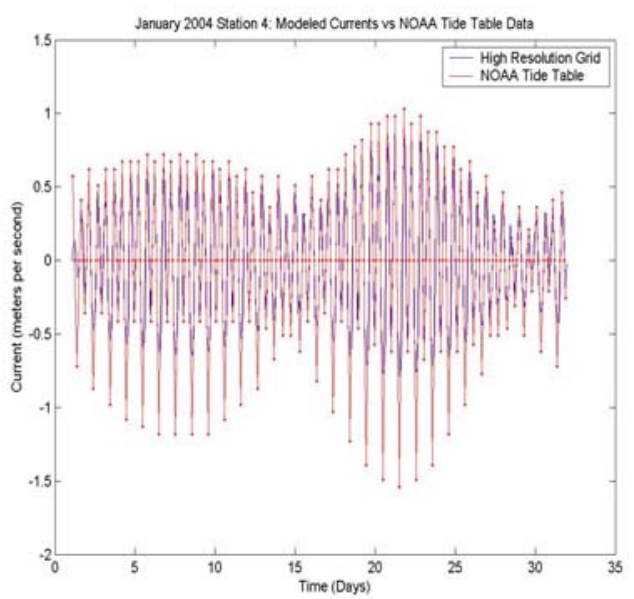

Fig. 6. Comparison between model generated (at Station-4) and NOAA tide table listed (at Station-1) maximum ebb and flood current velocities.

\section{APPLICATION TO THE DIVING OPERATIONS}

An additional and more useful example is to extend the same operation on the same day to include diving operations. One option to mine neutralization is to recover the mine using an explosive ordnance disposal (EOD) team. The scenario continues with the mine countermeasure finding and identifying a mine like object as an actual mine. The mine was found near a structural pylon of the Coronado Bridge (Station-4) so detonating it using the mine neutralization vehicle is not a desirable option. An EOD team is dispatched to retrieve the mine. Their operational threshold for currents is also operationally sensitive so a fictitious limit of $0.25 \mathrm{~m} \mathrm{~s}^{-1}$ (i.e., 0.5 knots) will be used for this example. There are four operational windows for diving operations in this scenario using the NOAA tide table data set at Station-1 (Fig. 8). They range from 0130 to 0320, 0800 to 0920,1530 to 1655 , and 2130 to 2330 . Again, compare these windows to those found using the modeled currents (Fig. 9) for the same location and the operation picture changes. The revised operational windows due to the modeled currents are 0130 to 0310,0810 to 0910,1650 to 1730 , and 2230 to 2320 . The first two windows were reduced slightly. More crucial changes occurred to the last two windows. The third window prediction was moved forward in time by an hour and twenty minutes and was reduced in duration from an hour and twenty-five minutes down to just forty minutes. Such changes in operating windows are crucial to successful operational planning to ensure mission success and safety to all personnel involved.
This example clearly illustrates the value added this hydrodynamic program can provide to effective mission planning.

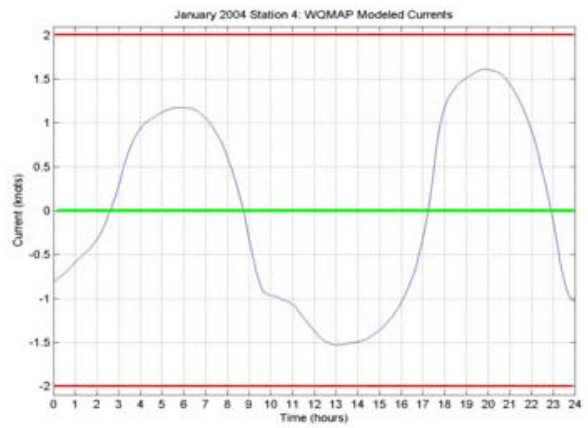

Fig. 7. Mission planning for mine countermeasure and mine hunting inside San Diego Bay (Station-4) using model (WQMAP) generated current velocities.

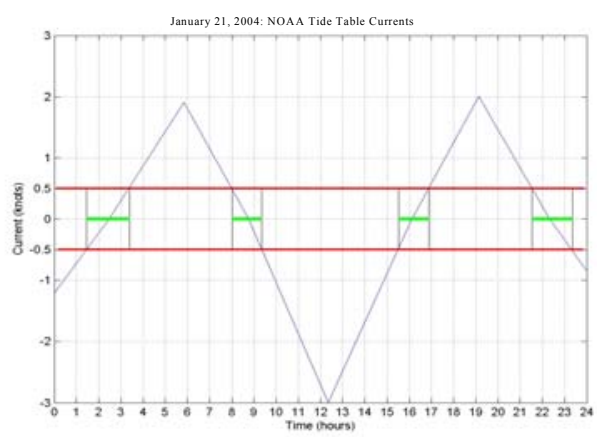

Fig. 8. Mission planning for the divers' operations inside San Diego Bay (Station-4) using NOAA tide table maximum ebb and flood current velocities at Station-1.

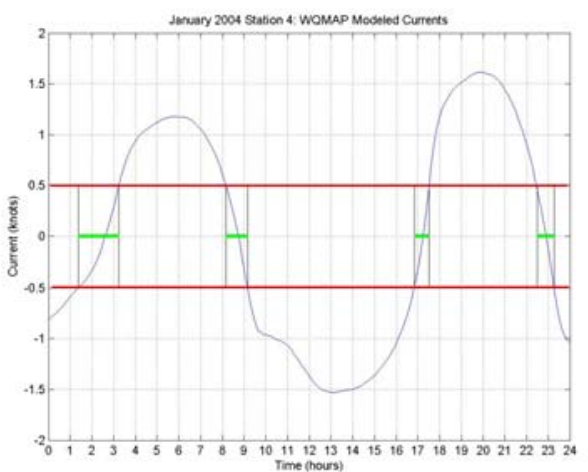

Fig. 9. Mission planning for divers' operations inside San Diego Bay (Station-4) using model (WQMAP) generated current velocities.

\section{CONCLUSIONS}

Ocean environmental conditions affect naval operations. Each warfare community has defined 
environmental thresholds and operating limits that restrict the execution of any intended maneuver. Accurate prediction of instantaneous velocity is essential in the littoral warfare such as in mine countermeasure, mine hunting, and divers' operations. The value-aided of using a hydrodynamic model (i.e., WQMAP) for the mission planning of the naval operations in San Diego Bay is demonstrated in this study in two aspects.

First, the mission planning changes without and with using the hydrodynamic model. Without the hydrodynamic model, the mission planning for the mine countermeasure, mine hunting, and divers' operations inside the bay is conducted using the maximum ebb and flood current speeds from the NOAA tide table (only one available at the entrance of the bay, i.e., Station-1). With the hydrodynamic model, the mission planning is conducted using the model-generated instantaneous current velocity data at the exact location (inside the bay) where the naval operations take place.

Second, the hydrodynamic model should be sufficiently accurate. Thus, thorough model verification should be conducted before it is used for the mission planning. For a tidal dominated littoral basin such as San Diego Bay, two kinds of verification should be conducted: (1) routine, and (2) compatibility verification. The routine verification is commonly used. The modeled data is compared with the observed data (such as ADCP data) inside the bay. The compatibility verification is to check if the model generated current velocities consist with that in the NOAA tide table near the open boundary. This study shows that WQMAP for San Diego Bay passes the compatibility verification with the relative mean error of $4.1 \%$.

As the warfare communities continue to advance in the realm of littoral warfare, so will the support for those communities. There continues to be an increasing demand to better model the much more complex coastal environment. The current use of the Naval Oceanographic Office's fleet survey teams can readily provide what is needed to validate these models for each littoral grid that may be needed. The primary mission of the fleet survey team is to obtain bathymetric data for navigational chart development. The same bathymetry can be imported into a boundary fitted grid of the same region to help model this environment. The fleet survey team can facilitate a successful model validation for a coastal area of interest by obtaining elevation data during a survey period to be used as forcing data for the open boundary cells defined within the model. Furthermore, the fleet survey team, by adding an ADCP to their inventory, can obtain routine verification data during their time frame of their hydrographic survey. With proper planning, this asset of the Naval Oceanographic Office can provide the warfare communities more than just an improved navigational product. The mission of the fleet survey team in conjunction with the Naval Oceanographic Office's modeling and forecasting divisions will be able to produce a series of small,
PC-based current prediction models that will be an invaluable benefit to future and unpredictable naval operations.

\section{ACKNOWLEDGMENTS}

This work was jointly supported by the Naval Oceanographic Office (document number: N6230604PO00123) and Naval Warfare System Command and the Naval Postgraduate School.

\section{REFERENCES}

[1] A. E. Armstrong, 2004. Prediction of instantaneous currents in San Diego Bay for naval applications. MS Thesis in Meteorology and Oceanography, Naval Postgraduate School, (Monterey), 56 pp.

[2] P.F. Wang, R.T. Cheng, K. Richter, E.S. Gross, D. Sutton, and J. W. Gartner, 1998. Modeling tidal hydrodynamics of San Diego Bay, California. Journal of the American Water Resources Association, 34 (5), 1123-1140.

[3] T. J. Peeling, 1975. A proximate biological survey of San Diego Bay, California. Naval Undersea Center, San Deigo, California, Report No. TP389.

[4] M. Muin, and M. L. Spaulding, 1996. Two-dimensional boundary fitted circulation model in spherical coordinates. Journal of Hydraulic Engineering, 122 (9), 512-520.

[5] M. Muin, and M. L. Spaulding, 1997. Three-dimensional boundary fitted circulation model. Journal of Hydraulic Engineering, 123 (1), 2-12.

[6] P.C. Chu., S.H. Lu, and Y.C. Chen, 2001. Evaluation of the Princeton Ocean Model using the South China Sea Monsoon Experiment (SCSMEX) data. Journal of Atmospheric and Oceanic Technology, 18, 1521-1539.

[7] P.C. Chu, C.W. Fan, and L.L. Ehret, 1997: Determination of open boundary conditions from interior observational data," Journal of Atmospheric and Oceanic Technology, 14, 723-734 